\title{
Arabidopsis NLP7 improves nitrogen use efficiency and yield in cotton
}

\author{
JAN Sami Ullah ${ }^{1 \dagger}$, LIAQAT Ayesha ${ }^{1 \dagger}$, ZHU Yonghong ${ }^{2}$, LI Jing ${ }^{2}$, ZHANG Huangyang ${ }^{2}$, ABDALLA Mohnad ${ }^{1}$, \\ WU Jie ${ }^{1}$, XIANG Chengbin ${ }^{1}$, WU Shenjie ${ }^{3^{*}}$ and ALFATIH Alamin ${ }^{1 *}$
}

\begin{abstract}
Background: Nitrogen $(\mathrm{N})$ is a required macronutrient for cotton growth and productivity. Excessive $\mathrm{N}$ fertilizers are applied in agriculture for crop yield maximization, which also generates environmental pollution. Improving crop $N$ use efficiency (NUE) is the most economical and desirable way of reducing fertilizer application and environmental pollution. NUE has been an important issue in cotton. So far there is no report on cotton NUE improvement via transgenic approach. Nin-like proteins (NLP) are transcription factors regulating NUE. We previously demonstrated that AtNLP7 improved NUE and biomass when overexpressed in Arabidopsis. However, it is not known whether AtNLP7 can be used to improve NUE in crops.

Results: To test the feasibility, we expressed AtNLP7 in cotton and evaluated NUE and yield of the transgenic cotton in the field. Transgenic cotton showed improved NUE and yield under both low and high N conditions. In addition, plant biomass, amount of absorbed N, N contents, activities of $\mathrm{N}$-assimilating enzymes, and the expression of $\mathrm{N}$-related marker genes were significantly increased in transgenic cotton compared with the wild type control, suggesting that AtNLP7 enhances NUE in cotton.
\end{abstract}

Conclusion: Together, our results demonstrate that AtNLP7 is a promising candidate to improve NUE and yield in cotton.

Keywords: Nitrogen, Nitrogen metabolism, Nitrogen use efficiency (NUE), Nin-like protein (NLP), AtNLP7, Cotton (Gossypium hirsutum)

\section{Background}

Cotton (Gossypium hirsutum L.) is a crucial fiber-producing cash crop for textile industry (Ding et al. 2020), livestock feed (Rogers et al. 2002), industrial lubricants (Durak and Karaosmanoglu 2004), and medicinal

\footnotetext{
*Correspondence: sj_wu@126.com; alfatih@ustc.edu.cn; 2725873001@qq.com

${ }^{\dagger}$ Jan SU and Liaqat A contributed equally to this work.

${ }^{1}$ School of Life Sciences, Division of Molecular \& Cell Biophysics, Hefei National Science Center for Physical Sciences at the Microscale, University of Science and Technology of China, The Innovative Academy of Seed Design, Chinese Academy of Sciences, Hefei, Anhui 230026, China

${ }^{3}$ College of Life Sciences, Shanxi Agricultural University, Taiyuan 030031,

China

Full list of author information is available at the end of the article
}

compounds (Egbuta et al. 2017). Global demand for cotton in 2019 was recorded as 27.31 million tons (Mt) while total production achieved $26.40 \mathrm{Mt}$ with average yield of 0.78 tons per hectare $\left(\mathrm{t} \cdot \mathrm{hm}^{-2}\right)(\mathrm{OECD} / \mathrm{FAO} 2020)$. In the next decade, cotton consumption of the world is anticipated to reach $29.17 \mathrm{Mt}$ which will be met with the yield of $0.83 \mathrm{t} \cdot \mathrm{hm}^{-2}$ until 2028 (OECD/FAO 2020). However, achieving the required productivity is limited by biological and environmental factors. One of such factors affecting cotton production is the availability and utilization of nitrogen $(\mathrm{N})$.

$\mathrm{N}$ has significant impact upon cotton growth (Karlen et al. 1996), yield (McConnell and Mozaffari 2005), and reproduction (Xue et al. 2008). It is an integral component of nucleic acids, proteins, coenzymes, chlorophyll, 
metabolites and phytohormones. $\mathrm{N}$ is consistently required in larger quantity to achieve higher yield (Hou et al. 2007). Previous studies have also associated high crop yield and overall plant biomass with $\mathrm{N}$ accumulation and assimilation (Basra and Malik 1984). Availability of $\mathrm{N}$ improves water use efficiency and salinity tolerance potential in irrigated cotton (Devkota et al. 2013). The overall cotton seed-fiber biomass undergoes synchronous and rapid elongation during seed development in the presence of $\mathrm{N}$ (Basra and Malik 1984). N deficiency leads to retarded cotton growth, senescence, and less boll production (Dong et al. 2012). Therefore, N fertilizers are commonly applied to enhance cotton productivity. However, excessive $\mathrm{N}$ causes delay in maturity as well as profuse vegetative development (Mng'omba et al. 2017). Plants cannot utilize all applied fertilizers. More than half of the applied $\mathrm{N}$ is lost into environment causing water and soil pollution (Zhang et al. 2018). Thus, an economical and optimal solution for reducing fertilizer input is to improve nitrogen use efficiency (NUE) of crops (Li et al. 2017; Alfatih et al. 2020; Niu et al. 2021).

NUE, an important agronomic trait, is described as the net amount of grain or biomass yield of a crop per unit of available N (Hawkesford 2014). Improving NUE by only $1 \%$ can significantly save about 1.1 billion dollars annually (Kant et al. 2012). Plant NUE is a complex trait determined by the processes of $\mathrm{N}$ sensing, uptake, assimilation, and utilization (Fan et al. 2017). First, soil nitrate is transported to the plant on the cellular level through slow anion channel associated homologues (SLAH), chloride channel (CLC) and nitrate transporters (NRTs) (Krapp et al. 2014; Fan et al. 2017). The absorbed nitrate is then reduced to ammonium by nitrate reductase (NR) and nitrite reductase (NiR). Ammonium is further assimilated into amino acids by the action of glutamate synthase (GOGAT) and glutamine synthetase (GS) (Masclaux Daubresse et al. 2010). A number of genes have been identified that could be manipulated for NUE improvement in plants, such as nitrate transporters, ammonium transporters, and key enzymes involved in $\mathrm{N}$ metabolism (Good et al. 2004) as well as transcriptional factors (Cai et al. 2021; Sandhu et al. 2021; Tiong et al. 2021).

Nodule inception (NIN) gene is required for nodule-formation in legume plants (Schauser et al. 1999). NIN encodes DNA-binding proteins with bZIP domain containing 60 amino acids highly conserved RWP-RK motif sequence (Borisov et al. 2003). Nodule inception (NIN)-like proteins (NLPs) are plant specific transcription factors (TFs) characterized by the presence of RWPRK domain and C-terminal PB1 domain (Konishi and Yanagisawa 2019). RWP-RK domain recognizes specific DNA element, PB1 domain serves in protein-protein interaction, while transcriptional activation is mediated by N-terminal region (Ge et al. 2018). NLPs bind to NRE (nitrate responsive cis element) in the promoter region and regulate the expression of $\mathrm{N}$-related genes (Konishi and Yanagisawa 2013). Previous studies revealed that AtNLP7 plays a key role in $\mathrm{N}$ sensing and metabolism (Castaings et al. 2009). Overexpression of AtNLP7 enhanced $\mathrm{N}$ assimilation and growth under $\mathrm{N}$ sufficient and limiting conditions in Arabidopsis (Yu et al. 2016). Thus, it can be exploited as potential candidate for improving NUE in cotton.

It is a great challenge to improve crop NUE by conventional breeding (Li et al. 2017; Niu et al. 2021). However, transgenic technology offers an efficient and effective alternative of improving NUE. For instance, rice NUE can be greatly improved by overexpressing OsNLPs (Alfatih et al. 2020; Wu et al. 2020). However, there is no report on cotton NUE improvement by transgenic approach. In this study, we developed transgenic cotton lines overexpressing AtNLP7 and tested the growth and NUE in laboratory as well as in the field. Our results showed that overexpression of AtNLP7 upregulated the expression of marker genes involved in $\mathrm{N}$ uptake and assimilation, improved N uptake and overall NUE in cotton as well as cotton yield in the field, suggesting that the function of AtNLP7 is well conserved in higher plants. Thus AtNLP7 is a promising candidate for improving cotton NUE.

\section{Results}

\section{AtNLP7 significantly improved the growth of cotton seedling}

To evaluate the role of $A t N L P 7$ in improving NUE of cotton, we generated transgenic cotton lines overexpressing $(\mathrm{OE})$ AtNLP7, and three homozygous transgenic lines (OE1, OE2 and OE3) were chosen for the study by confirming their AtNLP7 expression (Additional file 1: Fig. $\mathrm{S} 1)$. Transgenic lines and the wild type (CK) were grown in modified Kimura B solution with different concentrations of nitrate as the sole $\mathrm{N}$ source. All three transgenic lines showed significant improvement in growth as compared with the control (CK) in all tested $\mathrm{N}$ concentrations (Fig. 1A). The control plants (CK) did not show significant difference on root and shoot fresh weight under $0.2 \mathrm{mmol} \cdot \mathrm{L}^{-1}$ and $2.0 \mathrm{mmol} \cdot \mathrm{L}^{-1} \mathrm{~N}$ conditions in this developmental stage. Nevertheless, the OE lines exhibited significantly increased shoot and root weight, and root length under both low $\mathrm{N}$ and $\mathrm{N}$ rich conditions compared with CK (Fig. 1B). Furthermore, we compared the growth parameters of OE lines with CK cotton plants grown in soil. $\mathrm{OE}$ lines displayed increased plant height (Fig. 2A, C), leaf biomass (Fig. 2B, D), and chlorophyll contents (Fig. 2E, F) as compared with the CK. 


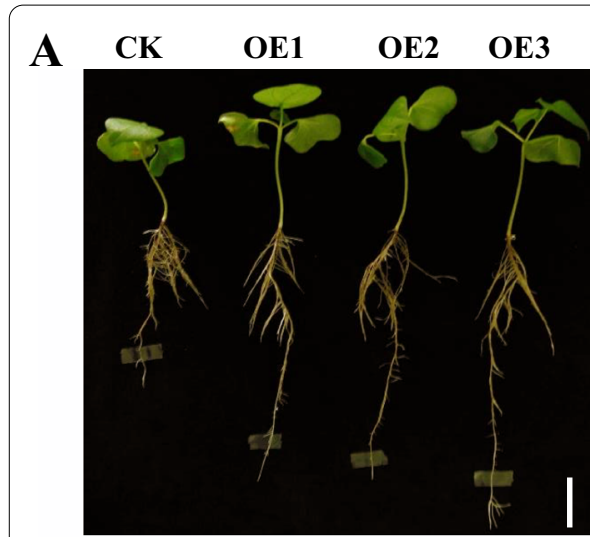

$\mathrm{KNO}_{3} /\left(0.02 \mathrm{mmol} \cdot \mathrm{L}^{-1}\right)$

B

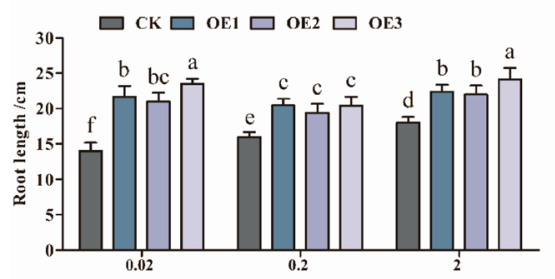

$\mathrm{KNO}_{3} /\left(\mathrm{mmol} \cdot \mathrm{L}^{-1}\right)$

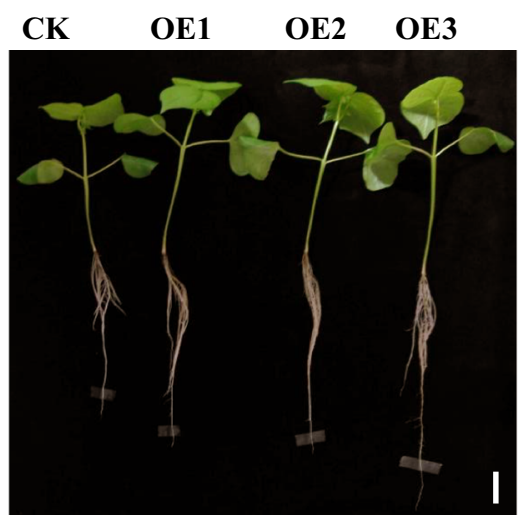

$\mathrm{KNO}_{3} /\left(0.2 \mathrm{mmol} \cdot \mathrm{L}^{-1}\right)$

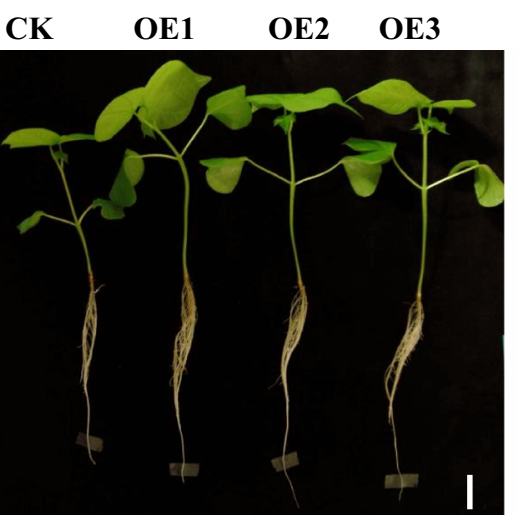

$\mathrm{KNO}_{3} /\left(2 \mathrm{mmol} \cdot \mathrm{L}^{-1}\right)$

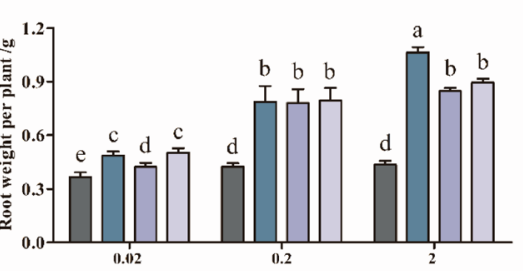

$\mathrm{KNO}_{3} /\left(\mathrm{mmol} \cdot \mathbf{L}^{-1}\right)$

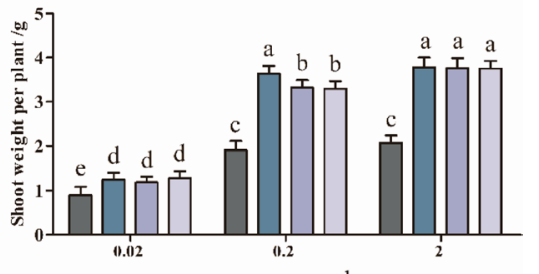

$\mathrm{KNO}_{3} /\left(\mathbf{m m o l} \cdot \mathrm{L}^{-1}\right)$

Fig. 1 AtNLP7 improved the growth of cotton seedling in hydroponic culture with different $\mathrm{N}$ levels. A Seedling of CK and transgenic cotton grown under different $\mathrm{N}$ levels. A representative seedling is shown for each line. Bar $=4 \mathrm{~cm}$. B Biomass of root and shoot. Results are average values \pm SD ( $n=3$ replicates, 16 plants per replicate). Letters denote significant differences $(P<0.05)$ from Duncan's multiple range tests

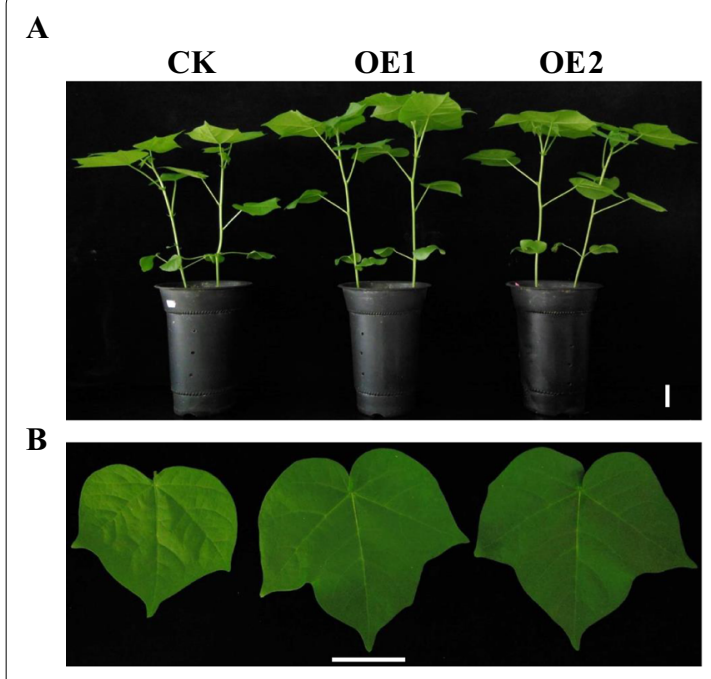

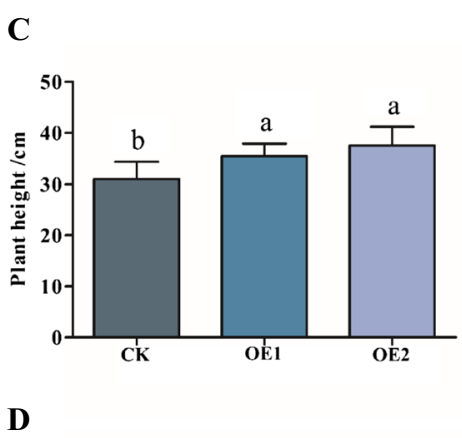

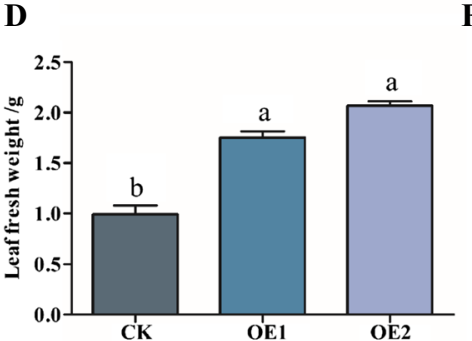

E
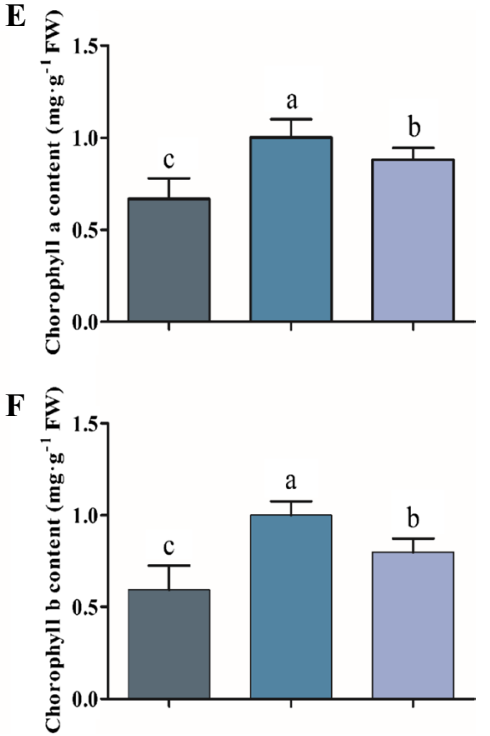

Fig. 2 Phenotype of soil-grown AtNLP7transgenic cotton. A Growth phenotype of three-weeks-old seedlings of CK and transgenic cotton grown in soil. A representative pot is shown for each line. Bar $=4 \mathrm{~cm}$. B Leaf comparison of three-week-old CK and transgenic cotton. A representative leaf is shown for each line. Bar $=4 \mathrm{~cm}$. (C-F) Growth related parameters including plant height $(\mathbf{C})$, leaf fresh weight (D), chlorophyll a content (E), and chlorophyll b content $(\mathbf{F})$ in CK and transgenic cotton. Results are average values \pm SD ( $n=3$ replicates, 16 samples per replicate). Letters denote significant differences $(P<0.05)$ from Duncan's multiple range tests 


\section{AtNLP7 improved cotton yield and NUE in field}

To evaluate the performance of $\mathrm{OE}$ lines in field, we conducted field trials for the OE lines and the wild type in the field conditions with application of $75,150,300$, and $375 \mathrm{~kg} \cdot \mathrm{hm}^{-2} \mathrm{~N}$ fertilizer as described in Methods and materials. Under $75,150,300$, and $375 \mathrm{~kg} \cdot \mathrm{hm}^{-2}$ concentrations, the yield of $\mathrm{OE}$ lines per plot increased by $14 \%, 25 \%, 19 \%$, and $9.6 \%$, respectively, over the control (Fig. 3A). Furthermore, the OE lines exhibited higher NUE under $150 \mathrm{~kg} \cdot \mathrm{hm}^{-2} \mathrm{~N}$ concentration with $22 \%$ increase over the control. Likewise, 14\% higher NUE was observed in OE when supplied with $75 \mathrm{~kg} \cdot \mathrm{hm}^{-2} \mathrm{~N}$ fertilizer while the NUE in OE was $15 \%$ higher when provided with $300 \mathrm{~kg} \cdot \mathrm{hm}^{-2} \mathrm{~N}$ fertilizer (Fig. 3B). However, no significant difference in NUE between transgenic lines and control was observed under $375 \mathrm{~kg} \cdot \mathrm{hm}^{-2} \mathrm{~N}$ concentration.

\section{AtNLP7 enhanced $\mathrm{N}$ uptake in cotton}

To investigate nitrate uptake of $\mathrm{OE}$ lines, we first conducted chlorate sensitivity assay. Chlorate is a toxic analogue of $\mathrm{KNO}_{3}$ and transported by the same nitrate transporters. Results in Fig. 4 showed that all OE and CK cotton plants grew well under $0 \mathrm{mmol} \cdot \mathrm{L}^{-1}$ chlorate condition. However, under $2.0 \mathrm{mmol} \cdot \mathrm{L}^{-1}$ chlorate conditions, the $\mathrm{OE}$ lines displayed phenotype of higher sensitivity to chlorate than $\mathrm{CK}$ as indicated by their survival rates (Fig. 4A, B), indicating that OE lines have higher $\mathrm{N}$ uptake ability. Second, we directly evaluated the nitrate acquisition ability of $\mathrm{CK}$ and $\mathrm{OE}$ plants by feeding $\mathrm{K}^{15} \mathrm{NO}_{3}$. And OE lines showed significantly higher uptake of $\mathrm{K}^{15} \mathrm{NO}_{3}$ (Fig. $4 \mathrm{C}$ ), consistent with the chlorate assay results.

\section{AtNLLP7 improve $\mathrm{N}$ assimilation in cotton}

Total $\mathrm{N}$ content, $\mathrm{C}$ content, and metabolite marker glutamate, nitrate reduction and assimilation related enzyme activities were measured and compared between transgenic and CK cotton under both high and low $\mathrm{N}$ concentrations. Increasing the provided nitrate concentration caused increment in $\mathrm{N}$ contents in both $\mathrm{CK}$ and $\mathrm{OE}$ cotton lines. Furthermore, $\mathrm{N}$ content was higher in $\mathrm{OE}$ lines as compared with $\mathrm{CK}$ under both high and low $\mathrm{N}$ concentrations (Fig. 5A). The $\mathrm{C}$ content was also found slightly higher in $\mathrm{OE}$ line than in $\mathrm{CK}$ under both low and normal concentrations of $\mathrm{KNO}_{3}$. Total C content in both $\mathrm{OE}$ and $\mathrm{CK}$ increased with the increasing $\mathrm{KNO}_{3}$ concentration from 0.02 to $2.0 \mathrm{mmol} \cdot \mathrm{L}^{-1}$ (Fig. $5 \mathrm{~B}$ ).

The nitrate contents in all cotton lines increased with increasing supply of $\mathrm{KNO}_{3}$ from 0.02 to $2.0 \mathrm{mmol} \cdot \mathrm{L}^{-1}$. However, nitrate contents in $\mathrm{OE}$ lines were found lower than those in $\mathrm{CK}$ under both low and high $\mathrm{N}$ concentrations (Fig. 5C), indicating that $\mathrm{KNO}_{3}$ was more quickly assimilated in transgenic plants. Glutamate content was increased in $\mathrm{OE}$ lines under both high and low concentrations of $\mathrm{N}$ despite the increasing activity of glutamine synthetase (Fig. 5D, H). This is probably due to fast production of glutamate compared with the amount of glutamine synthetase. The activities of enzymes in $\mathrm{N}$ assimilation, including nitrate reductase, nitrite reductase and glutamine synthetase were significantly higher in $\mathrm{OE}$ lines than in $\mathrm{CK}$ under both low and high $\mathrm{N}$ levels (Fig. 5F-H).

\section{AtNLP7 upregulated the expression of marker genes in N transport and assimilation}

The function of AtNLP7 is well conserved in cotton, which is supported by the nitrate responsive cis elements (NRE) in the promoter region ( $2 \mathrm{~kb})$ of the marker genes (Additional file 1: Table S1). To confirm if orthologous genes of AtNLP7 have evolved in cotton from common ancestor, we performed a BLAST using AtNLP7 protein sequence against cotton genome and found there are at least seven AtNLP7 orthologs in cotton (Additional file 1:

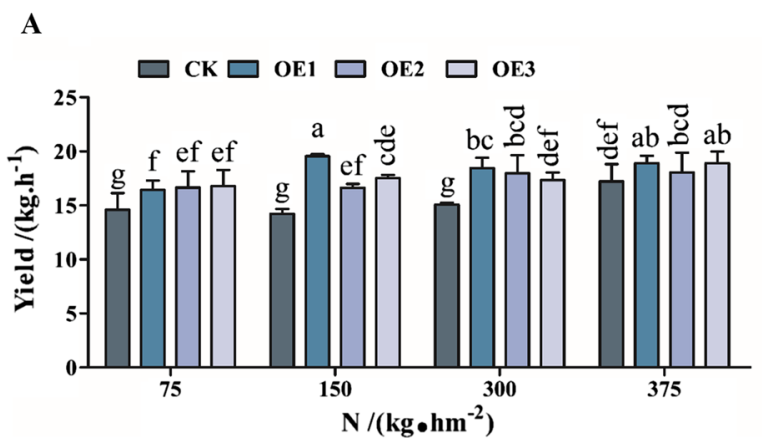

B

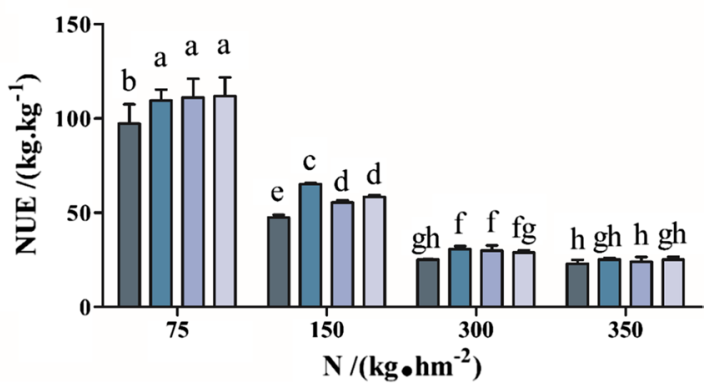

Fig. 3 AtNLP7 improved cotton yield and NUE in the field. Actual yield (A) and NUE (B) of transgenic cotton obtained under 75, 150, 300, and 375 $\mathrm{kg} \cdot \mathrm{hm}^{-2}$ supply of nitrogen. Results are average values $\pm S D(n=3$ replicates, 27 plants per replicate). Letters denote significant differences $(P<0.05)$ from Duncan's multiple range tests 

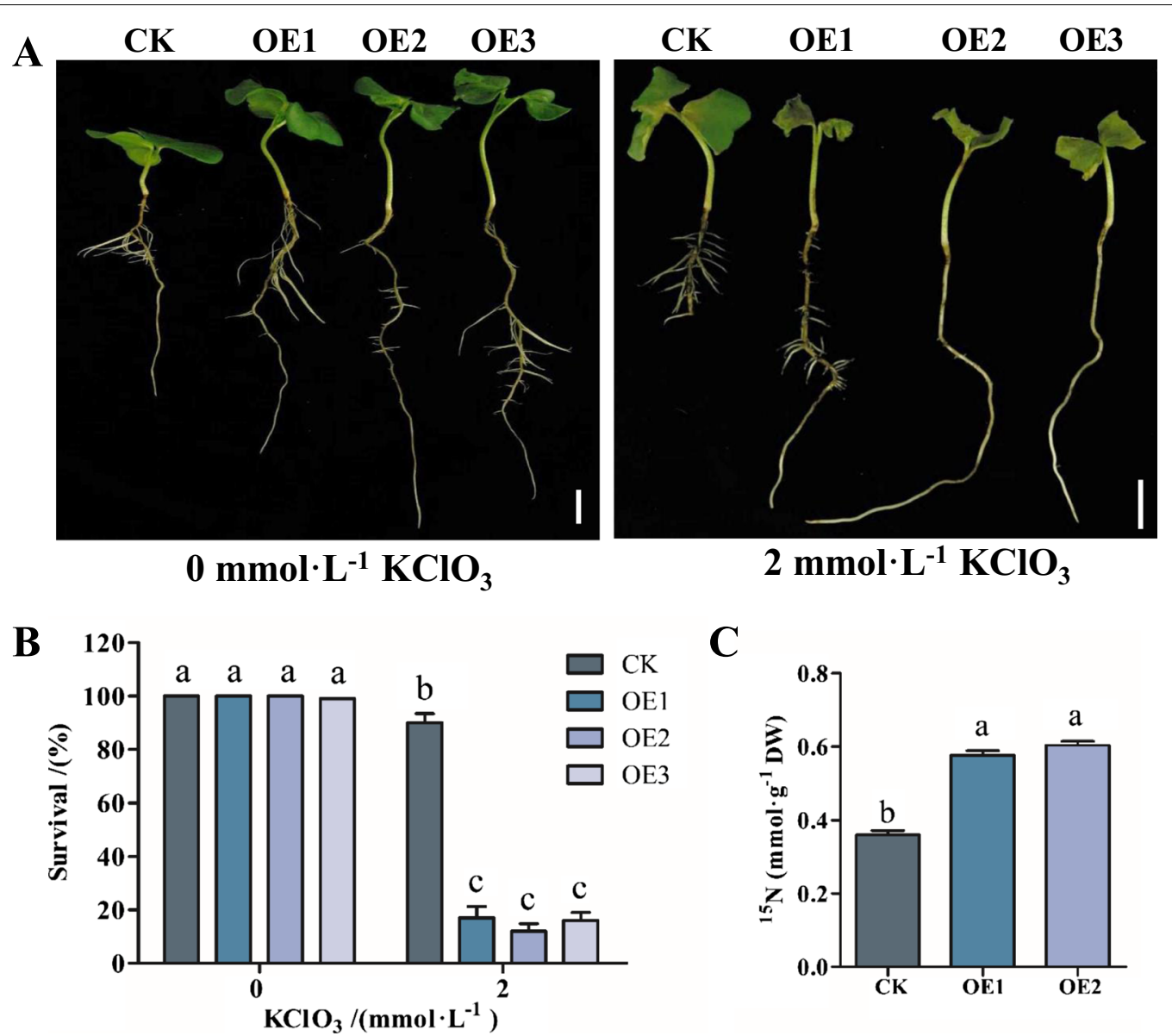

Fig. 4 AtNLP7 enhancef N uptake in cotton. A Chlorate sensitivity. A representative plant is shown after chlorate treatment. Bar $=4 \mathrm{~cm}$. B Survival $\%$ after chlorate treatment as in (A). Results are average values \pm SD ( $n=3$ replicates, 16 plants per replicate). Letters denote significant differences $(P<0.05)$ from Duncan's multiple range tests. C Accumulation of ${ }^{15} \mathrm{~N}$ isotope in 2-weeks-old seedlings. Results are average values $\pm S D(n=3$ replicates, 16 plants per replicate). Letters denote significant differences $(P<0.05)$ from Duncan's multiple range tests

Table S2). To confirm whether AtNLP7 in transgenic cotton regulates the same suit of genes as in Arabidopsis, we analyzed the expression levels of marker genes in nitrate transport, reduction and assimilation, including GhNRT1.1, GhNRT1.2, GhNRT2.1, GhNRT2.2, GhNIA1, GhAMT1, GhAMT2, and GhGS1.1, and found all the marker genes were significantly up-regulated in OE lines compared with the wild type, consistent with the phenotype of OE plants (Fig. 6).

\section{Discussion}

NUE improvement has been a major issue in cotton. A lot of work has been done to improve cotton NUE, mainly focusing on cultivation strategies (Du et al. 2016; Li et al. 2017; Zhang et al. 2018) and recently shift towards NUE evaluation of cotton cultivars andits application in breeding programs (Raun and Johnson 1999; Zhang et al. 2018; Iqbal et al. 2020). However, these strategies achieved limited success because they are laborious, costly and time-consuming. Transgenic approach is specially desirable to improve agronomic traits and has achieved tremendous success in cotton for example the $B t$ cotton for insect resistance (Zafar et al. 2020). Therefore, the identification and genetic manipulation of key NUE-enhancing genes become critical for improving cotton NUE.

In this study, we evaluated the Arabidopsis NLP7 in cotton NUE improvement. The AtNLP7 overexpression lines exhibited a significantly improved seedling growth under all $\mathrm{N}$ levels with increased seedling biomass, larger leaf and root system (Figs. 1, 2), which greatly benefit seedling establishment. The field trial also showed that the AtNLP7 overexpression significantly improved both cotton NUE and yield (Fig. 3). We further showed that AtNLP7 overexpression upregulated the expression of genes related to $\mathrm{N}$ uptake and assimilation in cotton (Fig. 6), result in increasing $\mathrm{N}$ uptake and assimilation (Figs. 4, 5), and ultimately improving cotton NUE and yield. 


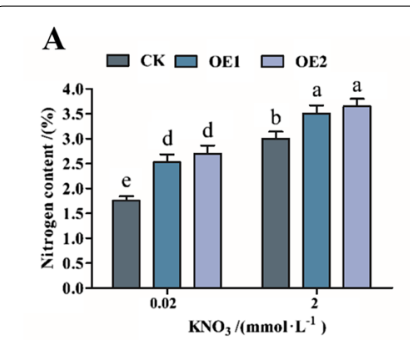

$\mathbf{E}$

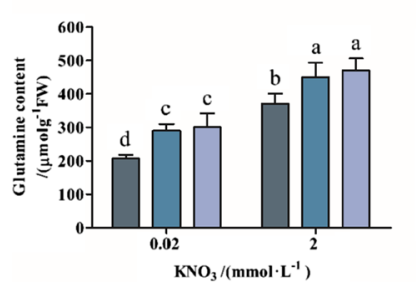

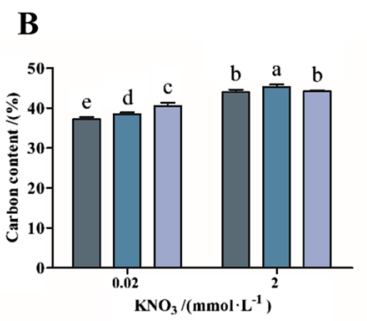

F

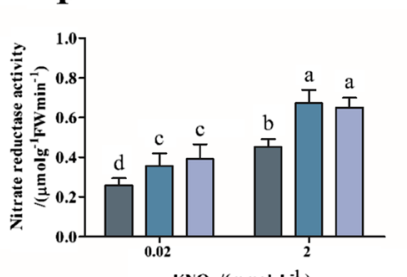

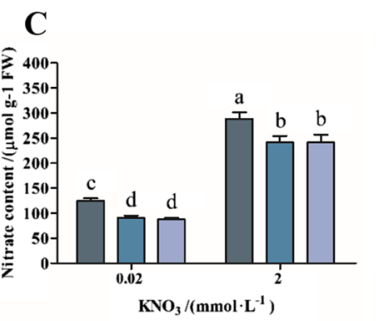

G

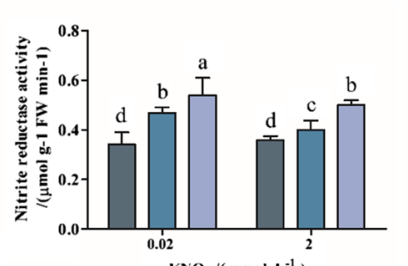

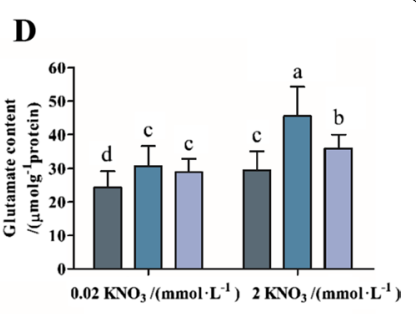

$\mathbf{H}$

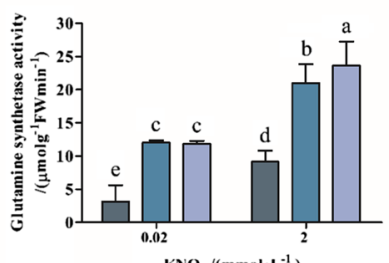

Fig. 5 AtNLP7 improved N assimilation in cotton. A and B Content of nitrogen $(\mathbf{A})$ and carbon (B). Results are average values $\pm S D(n=3$ replicates). Letters denote significant differences $(P<0.05)$ from Duncan's multiple range tests. $\mathbf{C}-\mathbf{E}$ Content of nitrate $(\mathbf{C})$, glutamate $(\mathbf{D})$, and glutamine $(\mathbf{E})$. Results are average values $\pm S D(n=3$ replicates). Letters denote significant differences $(P<0.05)$ from Duncan's multiple range tests. $\mathbf{F}-\mathbf{H}$ Enzyme activity of nitrate reductase $(\mathbf{F})$, nitrite reductase $(\mathbf{G})$, and glutamate synthase $(\mathbf{H})$, in transgenic cotton compared with CK. Results are average values \pm SD $(n=3$ replicates). Letters denote significant differences $(P<0.05)$ from Duncan's multiple range tests
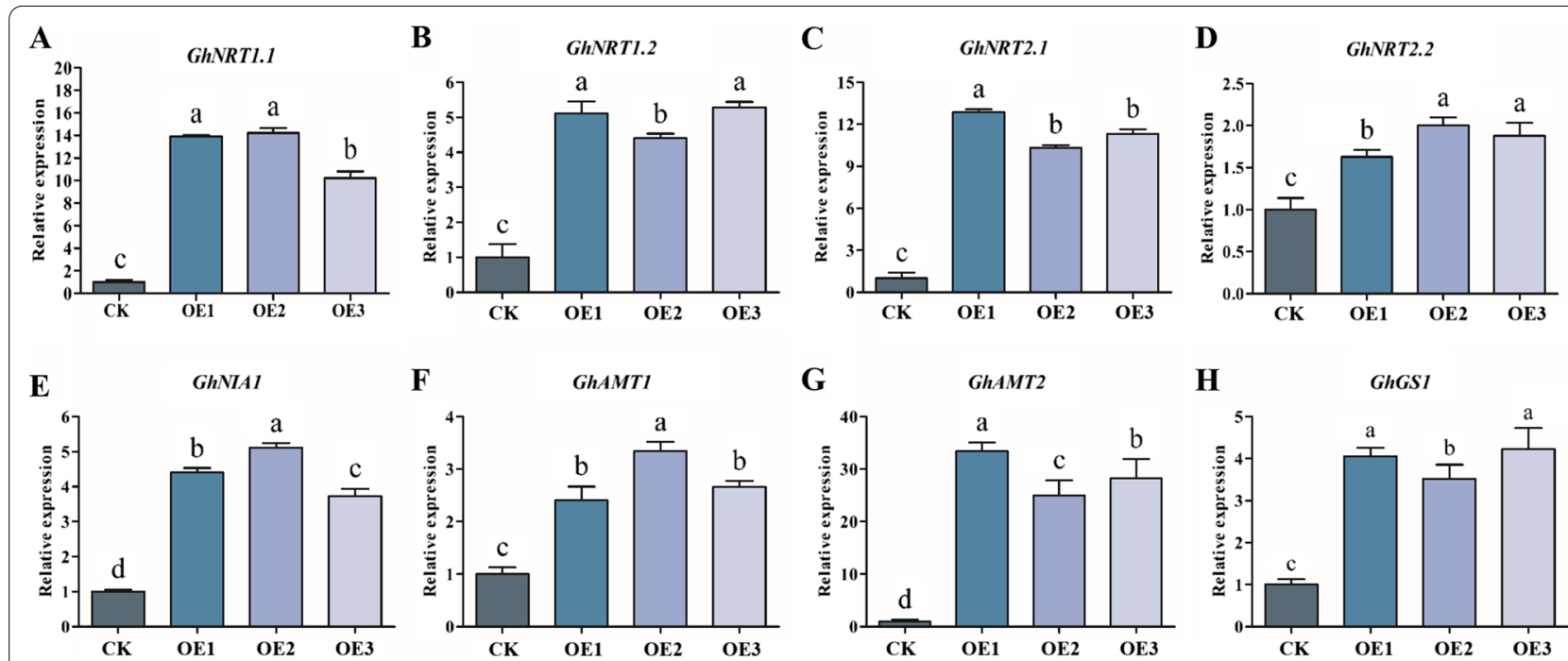

Fig. 6 AtNLP7 upregulated N-related genes. Two-weeks-old cotton plants grown on medium containing $2 \mathrm{mmol} \cdot \mathrm{L}^{-1} \mathrm{KNO}_{3}$ were used for RT-PCR analysis of GhNRT1.1 (A), GhNRT1.2 (B), GhNRT2.1 (C), GhNRT2.2 (D), GhNIA1 (E), GhAMT1 (F), GhAMT2 (G), GhGS1 (H). GhHis3 was used as internal control. Results are average values $\pm S D$ ( $n=3$ replicates). Letters denote significant differences $(P<0.05)$ from Duncan's multiple range tests

According to studies reported earlier, there are in total of 60, 61, and 105 NLP genes in G. arboreum, G. raimondii, and $G$. hirsutum, respectively (Magwanga et al. 2019). We performed BLAST (as shown in Additional file 1: Table S2) which showed that 7 orthologs of AtNLP7 are found in cotton and these 7 genes include GhNLP2, 4, 5, 6, 7, 8, and GhNLP9 (Additional file 1: Table S2). Moreover, the NREs in the promoter regions
(2 kb) of these cotton genes (Additional file 1: Table S1) are similar to those found in Arabidopsis which suggest that AtNLP7 could directly activate the expression of cotton genes by binding to NRE.

Other regulatory genes have been identified to improve NUE such as SNF1-related kinase (SnRK) in tomato (Wang et al. 2012), bHLH transcription factor in soybean (Chiasson et al. 2014), NAC transcription factor in wheat 
(Uauy et al. 2006) as well as OsNLPs in rice (Alfatih et al. 2020; Wu et al. 2020). These genes are candidates for genetically improving cotton NUE as well.

Assimilation of $\mathrm{N}$ and $\mathrm{C}$ are tightly co-regulated processes which indicate that NUE, along with $\mathrm{N}$ assimilation, also admits $\mathrm{C}$ metabolism (Chardon et al. 2012). Thus, it is agreeable that optimizing plant growth, development, and yield involves simultaneous improvements in both $\mathrm{N}$ and $\mathrm{C}$ utilization efficiencies. We found similar coordination among $\mathrm{C}$ and $\mathrm{N}$ assimilations indicated by higher accumulation of $\mathrm{C}$ and $\mathrm{N}$ in AtNLP7 overexpressing cotton. Expression of AtNLP7 in cotton showed higher chlorophyll contents which may pose direct impact upon $\mathrm{C}$-fixation ( $\mathrm{Yu}$ et al. 2016). A well-balanced $N / C$ is significantly helpful in improving NUE.

The AtNLP7-enhanced NUE in cotton was supported by the data of total $\mathrm{N}$ content, $\mathrm{C}$ content, and two metabolite markers (glutamate and glutamine) for $\mathrm{N}$ assimilation and utilization (Fig. 5). Higher $\mathrm{N}$ as well as $\mathrm{C}$ content were found in transgenic cotton as compared with CK. The nitrate contents were lower in $\mathrm{OE}$ plants than in $\mathrm{CK}$, however, total nitrate contents increased with increasing supply of $\mathrm{KNO}_{3}$ from 0.02 to $2.0 \mathrm{mmol} \cdot \mathrm{L}^{-1}$ (Fig. $5 \mathrm{C}$ ). These results indicated that more $\mathrm{N}$ was absorbed in $\mathrm{OE}$ cotton than $\mathrm{CK}$, and more $\mathrm{KNO}_{3}$ was assimilated in OE plants thus reducing their net content. The glutamate (Glu) content was also found lower in CK. The net Glu contents of both control and transgenic lines were found higher at higher concentration of $\mathrm{KNO}_{3}$ (Fig. 5D). Meanwhile, glutamine (Gln) contents increased significantly in transgenic cotton than in CK while net Gln content were higher on high $\mathrm{N}$ supply than lower $\mathrm{N}$ concentration (Fig. 5E). These results suggested that the assimilation of N in NLP7 OE line was increased compare with CK. (Fig. 5F-H).

The metabolic data are consistent with and supported by the expression analysis of $\mathrm{N}$ metabolism marker genes including GhNRT1.1, GhNRT1.2, GhNRT2.1, GhNRT2.2, GhNIA1, GhAMT1, GhAMT2, and GhGST1.1, which were up-regulated in OE lines compared with CK (Fig. 6). Taken together, these results suggest that the function of AtNLP7 is well conserved in cotton.

\section{Conclusions}

In conclusion, we have demonstrated that the function of Arabidopsis NLP7 is well conserved in cotton. Overexpressing AtNLP7 up-regulates $\mathrm{N}$ uptake and assimilation, and improves yield and NUE in cotton. Therefore NLP7 is a promising candidate gene for cotton NUE and yield improvement.

\section{Methods and materials Plant transformation}

Full length cDNA of AtNLP7 was cloned in the binaryvector (pCB2004) containing CaMV 35 S promoter, and Agrobacterium-mediated cotton transformation was adopted as described by Lei et al. (2007). R15 cultivar of upland cotton (Gossypium hirsutum) was used as the recipient. The plantlets were generated and transferred to pots for further growth. Subsequently, the primary shoots of transformed $\mathrm{T}_{0}$ plants were grafted into mature cotton plants of the wild type to get $\mathrm{T}_{1}$ seeds as previously described in Arabidopsis (Yu et al. 2016).

\section{Plant growth conditions}

Seeds were disseminated for 4 days in soil and then transferred into Kimura B solution for hydroponic culture and replaced with fresh medium on alternate days (Ehara et al. 1990). According to $\mathrm{N}$ requirements by plants and studies reported earlier (Shah et al. 2017; Alfatih et al. 2020), three levels of $\mathrm{N}$ concentrations were selected to treat $\mathrm{CK}$ and transgenic cotton lines to study their growth rates (normal $=2 \mathrm{mmol} \cdot \mathrm{L}^{-1} \mathrm{KNO}_{3}$, medium $=0.2 \mathrm{mmol} \cdot \mathrm{L}^{-1} \mathrm{KNO}_{3}$, Low $=0.02 \mathrm{mmol} \cdot \mathrm{L}^{-1}$ $\left.\mathrm{KNO}_{3}\right)$ at $28{ }^{\circ} \mathrm{C}$, with photoperiod of $8 \mathrm{~h}$ dark and $16 \mathrm{~h}$ light, relative humidity $70 \%$, and $250 \mu \mathrm{mol} \cdot \mathrm{m}^{-2} \cdot \mathrm{s}^{-1}$ light intensity. For analyzing soil-grown phenotype, plants were grown in soil (Pindstrup organic mixes, PindstrupMosebrug A/S, Fabriksvej 2, 8550 Ryomgaard, Denmark) with similar photoperiod time and temperature as for the hydroponic growth condition.

\section{RNA isolation and qRT-PCR}

Total RNA was isolated using Eastep Super Total RNA Extraction Kit (Promega Biotech Co. Ltd. Beijing). Isolated RNA $(1 \mu \mathrm{g})$ from each sample was subjected to reverse transcription reaction. For expression analysis of AtNLP7, gene specific primers were used with cDNA template for qRT-PCR. Cotton GhHis3 (AF024716) was used as internal control and quantitative RT-PCR was carried out according to reported protocol (Alfatih et al. 2020). Expression levels of GhNRT1.1, GhNRT1.2 , GhNRT2.1, GhNRT2.2 (nitrate transporters), GhNIA1 (nitrite transporter1), GhAMT1, GhAMT2 (ammonium transporters), and GhGS1 (glutamine synthetase1) were checked by using gene specific primers listed in Additional file 1: Table S3.

Determination of chlorophyll, nitrate, and carbon contents Samples (200 mg) from 4 weeks old plant leaves were taken from control and transgenic cotton plants grown 
in soil for determination of chlorophyll contents. Samples were frozen in liquid nitrogen and then kept in $5 \mathrm{~mL}$ of absolute ethanol (99.9\%) followed by heating for $20 \mathrm{~min}$ at $80{ }^{\circ} \mathrm{C}$ in water bath. Total amount of chlorophyll was checked from absorbance reading by using appropriate extinction coefficient in alcohol extracts. Total chlorophyll (mg.g ${ }^{-1}$ fresh weight) content was quantified using protocol reported earlier (Choe and Thimann 1975). Cellular nitrates were isolated in $50 \mathrm{mmol} \cdot \mathrm{L}^{-1} \mathrm{HEPES}-\mathrm{KOH}$ (pH 7.4) and quantified using established protocol (Cataldo et al. 1975). Oven-dried plant materials were processed in CHNS analyzer (Vario EL III model, Hanau, Elementar, Germany) using the manufacturer's guideline for quantification of total $\mathrm{C}$ and $\mathrm{N}$ content.

\section{Metabolite and enzyme activity assays}

The metabolites and enzyme activities analyses were performed in cotton seedlings treated hydroponically for 16 days with different dilutions of $\mathrm{N}\left(0.02 \mathrm{mmol} \cdot \mathrm{L}^{-1}\right.$ and $2 \mathrm{mmol} \cdot \mathrm{L}^{-1} \mathrm{KNO}_{3}$ ). To identify the total of $\mathrm{N}$ and $\mathrm{C}$ content, plants were dried in oven and measured using an CHNS analyzer (Vario EL III model, Elementar, Hanau, Germany) according to the manufacturer's instructions. Nitrate content was measured using assay kits (Su Zhou Keming Bioengineering Company, China), following the manufacturer's instructions. Glutamate content was measured using assay kits (Nanjing Jiancheng Bioengineering Institute and affandi-e.com, Shanghai respectively). The maximal NR in vitro activity was checked using the reported protocol (Ferrario-Mery et al. 1998), while enzymes activities of NR, NiR, and GS were checked using enzyme-coupled spectrophotometer assay kit (Su Zhou Keming Bioengineering Company, China) according to manufacturer's guidelines (Cai et al. 2009).

\section{Chlorate sensitivity assay}

Seedlings, initially grown in Kimura B solution $\left(2 \mathrm{mmol} \cdot \mathrm{L}^{-1} \mathrm{KNO}_{3}\right.$ ) for 4 days, were then treated for 6 days with $2.0 \mathrm{mmol} \cdot \mathrm{L}^{-1}$ chlorate. Treated seedlings were subsequently recovered for two days in Kimura B solution with $2.0 \mathrm{mmol} \cdot \mathrm{L}^{-1} \mathrm{KNO}_{3}$. The chlorate treated plants that died after recovery in Kimura B solution were counted as dead. Survival rate (\%) is calculated as (total treated plants - dead plants)/total treated plants"100.

\section{Determination of $\mathrm{N}$ uptake using ${ }^{15} \mathrm{~N}$-nitrate}

$\mathrm{N}$ uptake by cotton seedlings using ${ }^{15} \mathrm{~N}$-labeled $\mathrm{KNO}_{3}$ (Sigma-Aldrich, No. 335134, 99\% ${ }^{15} \mathrm{~N}$ ) was performed as previously described (Lin et al. 2008). Briefly, seedlings grown in Kimura B solution for 10 days were shifted to $0.1 \mathrm{mmol} \cdot \mathrm{L}^{-1} \mathrm{CaSO}_{4}$ for one minute followed by incubation for $30 \mathrm{~min}$ in modified MS $\left(5 \mathrm{mmol} \cdot \mathrm{L}^{-1} \mathrm{~K}^{15} \mathrm{NO}_{3}\right.$ of $99 \%{ }^{15} \mathrm{~N}$ as the only $\mathrm{N}$ source) nutrient solution, and finally kept for one minute in $0.1 \mathrm{mmol} \cdot \mathrm{L}^{-1} \mathrm{CaSO}_{4}$. Seedlings were oven-dried at $70{ }^{\circ} \mathrm{C}$ to a constant weight and then grinded. Total ${ }^{15} \mathrm{~N}$ content was measured through continuous flow isotope ratio mass spectrometer (Thermo-MAT253) conjugated with elemental analyzer (Flash2000 HT, Thermo Fisher Scientific, Inc., USA).

\section{Field test of cotton}

Field trials for the evaluation of transgenic AtNLP7 cotton performance (yield and NUE) under different $\mathrm{N}$ concentrations were conducted at the Experimental Station of Shanxi Academy of Agricultural Sciences, Yuncheng, Shanxi Province, China from April to September 2021. Three plots or replicates for each variety were set, and $75,150,300$, and $375 \mathrm{~kg} \cdot \mathrm{hm}^{-2}$ urea fertilizer in addition of $375 \mathrm{~kg} \cdot \mathrm{hm}^{-2}$ of superphosphate was added to each treatment, respectively. Cotton plants were grown with a density of 27 plants per row, and 4 rows per plot. Plot dimensions were maintained with row length of $7.41 \mathrm{~m}$ and $0.675 \mathrm{~m}$ row spacing. Total test area is $240 \mathrm{~m}^{2}$ with 52500 plants $\cdot \mathrm{hm}^{-2}$ density and average plant spacing of $0.274 \mathrm{~m}$. Border plants were excluded to avoid marginal effects, and the variation in field trials were reduced by applying fertilizers evenly in each plot. The cotton fiber yield was calculated by weighing the harvested cotton while the NUE was calculated using the following formula: $\mathrm{NUE}=$ cotton yield / amount of applied $\mathrm{N}$ fertilizer.

\section{Accession numbers}

Sequence data from this article can be found in the Arabidopsis TAIR database (https://www.arabidopsis.org/) or The National Center for Biotechnology Information (www.ncbi.nlm.nih.gov/) under the following accession numbers: AtNLP7: AT4G24020, GhHIS3: LOC107951735, GhNRT1.1: LOC107920453, GhNRT1.2: LOC107918724, GhNRT2.1: LOC107942169, GhNRT2.2: LOC107958556, GhNIA1: LOC107910262, GhGS1: LOC107928854, GhAMT1:LOC107892566, and GhAMT2: LOC107938932.

\section{Supplementary Information}

The online version contains supplementary material available at https://doi. org/10.1186/s42397-021-00110-7.

Additional file 1. Fig. S1. Verification of AtNLP7 transgenic cotton lines. Table S1. NRE consensus sequence TGACCC...N (9-12)...AAGAG in the promoter of the marker genes. Table S2. The BLAST search result of AtNLP7 protein sequence against cotton genome. Table S3. List of primers used for reverse-transcription PCR.

\section{Acknowledgements}

This work was supported by grants from Ministry of Science and Technology of China (Grant No. 2016ZX08005004-003). 


\section{Authors' contributions}

Alfatih A, Wu S, and Xiang CB designed the experiments. Jan SU, Liaqat A, Jie W, Abdalla M, and Alamin A performed most of the experiments and data analyses. Zhu Y, Li J, Zhang H, and Wu S conducted field trials and data analyses. Jan SU, Liaqat A, and Alfatih A wrote the manuscript. Alfatih A, Wu S, and Xiang CB revised the manuscript and supervised the project. All authors read and approved the final manuscript

\section{Funding}

Ministry of Science and Technology of China (Grant No. 2016ZX08005004-003).

\section{Availability of data and materials}

All data generated or analyzed during this study are included in this published article [and its supplementary information files].

\section{Declarations}

Ethics approval and consent to participate

Not applicable.

\section{Consent for publication}

Not applicable.

\section{Competing interests}

The authors declare that they have no competing interests.

\section{Author details}

'School of Life Sciences, Division of Molecular \& Cell Biophysics, Hefei National Science Center for Physical Sciences at the Microscale, University of Science and Technology of China, The Innovative Academy of Seed Design, Chinese Academy of Sciences, Hefei, Anhui 230026, China. ${ }^{2}$ Institute of Cotton Research, Shanxi Agricultural University, Yuncheng 044000, China. ${ }^{3}$ College of Life Sciences, Shanxi Agricultural University, Taiyuan 030031, China.

Received: 29 August 2021 Accepted: 8 December 2021

Published online: 06 January 2022

\section{References}

Alfatih A, Wu J, Zhang ZS, et al. Rice NIN-LIKE PROTEIN 1 rapidly responds to nitrogen deficiency and improves yield and nitrogen use efficiency. J Exp Bot. 2020;71(19):6032-42. https://doi.org/10.1093/jxb/eraa292.

Basra AS, Malik CP. Development of the cotton fiber. Int Rev Cytol. 1984;89:65-113. https://doi.org/10.1016/S0074-7696(08)61300-5.

Borisov AY, Madsen LH, Tsyganov VE, et al. The Sym35 gene required for root nodule development in pea is an ortholog of Nin from Lotus japonicus. Plant Physiol. 2003;131(3):1009-17. https://doi.org/10.1104/pp.102. 016071.

Cai H, Zhou Y, Xiao J, et al. Overexpressed glutamine synthetase gene modifies nitrogen metabolism and abiotic stress responses in rice. Plant Cell Rep. 2009;28(3):527-37. https://doi.org/10.1007/s00299-008-0665-z.

Cai T, Chen Y, Pan J, et al. Improved crop management achieved high wheat yield and nitrogen use efficiency. Int J Plant Prod. 2021;15(2):317-24. https://doi.org/10.1007/s42106-021-00139-3.

Castaings L, Camargo A, Pocholle D, et al. The nodule inception-like protein 7 modulates nitrate sensing and metabolism in Arabidopsis. Plant J. 2009;57(3):426-35. https://doi.org/10.1111/j.1365-313X.2008.03695.x.

Cataldo DA, Maroon M, Schrader LE, et al. Rapid colorimetric determination of nitrate in plant tissue by nitration of salicylic acid. Commun Soil Sci Plan. 1975;6(1):71-80. https://doi.org/10.1080/00103627509366547.

Chardon F, Noël V, Masclaux DC. Exploring NUE in crops and in Arabidopsis ideotypes to improve yield and seed quality. J Exp Bot. 2012;63(9):3401-12. https://doi.org/10.1093/jxb/err353.

Chiasson DM, Loughlin PC, Mazurkiewicz D, et al. Soybean SAT1 (Symbiotic Ammonium Transporter 1) encodes a bHLH transcription facto involved in nodule growth and $\mathrm{NH}_{4}^{+}$transport. Proc Natl Acad Sci. 2014:111(13):4814-19. https://doi.org/10.1073/pnas.1312801111.
Choe HT, Thimann KV. The metabolism of oat leaves during senescence: III. The senescence of isolated chloroplasts. Plant Physiol. 1975:55(5):82834. https://doi.org/10.1104/pp.55.5.828.

Devkota M, Martius C, Lamers JPA, et al. Tillage and nitrogen fertilization effects on yield and nitrogen use efficiency of irrigated cotton. Soil till Res. 2013;134:72-82. https://doi.org/10.1016/j.still.2013.07.009.

Ding $Y$, Tang $S$, Han $R$, et al. Iron oxides nanobelt arrays rooted in nanoporous surface of carbon tube textile as stretchable and robust electrodes for flexible supercapacitors with ultrahigh areal energy density and remarkable cycling-stability. Sci Rep. 2020;10(1):11023. https://doi.org/10.1038/ s41598-020-68032-z.

Dong $\mathrm{H}$, Li W, Eneji AE, et al. Nitrogen rate and plant density effects on yield and late-season leaf senescence of cotton raised on a saline field. Field Crops Res. 2012;126:137-44. https://doi.org/10.1016/j.fcr.2011.10.005.

Du X, Chen B, Zhang Y, et al. Nitrogen use efficiency of cotton (Gossypium hirsutum L.) as influenced by wheat-cotton cropping systems. Eur J Agron. 2016;75:72-9. https://doi.org/10.1016/j.eja.2016.01.001.

Durak E, Karaosmanoglu F. Using of cotton seed oil as an environmentally accepted lubricant additive. Energy Sour. 2004;26(7):611-25. https://doi. org/10.1080/00908310490438605.

Egbuta MA, Mclntosh S, Waters DLE, et al. Biological importance of cotton byproducts relative to chemical constituents of the cotton plant. Molecules. 2017;22(1):93. https://doi.org/10.3390/molecules22010093.

Ehara $\mathrm{H}$, Tsuchiya M, Ogo T. Fundamental growth response to fertilizer in rice plants: I. Varietal difference in the growth rate at the seedling stage. Jpn J Crop Sci. 1990;59(3):426-34. https://doi.org/10.1626/jcs.59.426.

Fan X, Naz M, Fan X, et al. Plant nitrate transporters: from gene function to application. J Exp Bot. 2017;68(10):2463-75. https://doi.org/10.1093/jxb/ erx011.

Ferrario-Mery S, Valadier $\mathrm{MH}$, Foyer $\mathrm{CH}$. Overexpression of nitrate reductase in tobacco delays drought-induced decreases in nitrate reductase activity and mRNA. Plant Physiol. 1998;117(1):293-302. https://doi.org/10.1104/ pp.117.1.293.

Ge M, Liu Y, Jiang L, et al. Genome-wide analysis of maize NLP transcription factor family revealed the roles in nitrogen response. Plant Growth Regul. 2018;84(1):95-105. https://doi.org/10.1007/s10725-017-0324-x.

Good AG, Shrawat AK, Muench DG. Can less yield more? Is reducing nutrient input into the environment compatible with maintaining crop production? Trends Plant Sci. 2004;9(12):597-605. https://doi.org/10.1016/j.tplan ts.2004.10.008

Hawkesford MJ. Reducing the reliance on nitrogen fertilizer for wheat production. J Cereal Sci. 2014;59(3):276-83. https://doi.org/10.1016/j.jcs.2013. 12.001.

Hou Z, Li P, Li B, et al. Effects of fertigation scheme on N uptake and N use efficiency in cotton. Plant Soil. 2007;290(1):115-26. https://doi.org/10. 1007/s11104-006-9140-1.

lqbal A, Dong Q, Wang X, et al. Variations in nitrogen metabolism are closely linked with nitrogen uptake and utilization efficiency in cotton genotypes under various nitrogen supplies. Plants. 2020;9(2):250. https://doi. org/10.3390/plants9020250.

Kant S, Seneweera S, Rodin J, et al. Improving yield potential in crops under elevated $\mathrm{CO}_{2}$ : integrating the photosynthetic andnitrogen utilization efficiencies. Front Plant Sci. 2012;3:162. https://doi.org/10.3389/fpls.2012. 00162.

Karlen DL, Hunt PG, Matheny TA. Fertilizer 15nitrogen recovery by corn, wheat, and cotton grown with and without pre-plant tillage on norfolk loamy sand. Crop Sci. 1996;36(4):975-81. https://doi.org/10.2135/cropsci1996. 0011183X003600040026x.

Konishi M, Yanagisawa S. Arabidopsis NIN-like transcription factors have a central role in nitrate signalling. Nat Commun. 2013;4(1):1617. https://doi. org/10.1038/ncomms2621.

Konishi M, Yanagisawa S. The role of protein-protein interactions mediated by the PB1 domain of NLP transcription factors in nitrate-inducible gene expression. BMC Plant Biol. 2019;19(1):90. https://doi.org/10.1186/ s12870-019-1692-3.

Krapp A, David LC, Chardin C, et al. Nitrate transport and signalling in Arabidopsis. J Exp Bot. 2014;65(3):789-98. https://doi.org/10.1093/jxb/eru001.

Lei ZY, Zhao P, Cao MJ, et al. High-throughput binary vectors for plant gene function analysis. J Integr Plant Biol. 2007;49(4):556-67. https://doi.org/10. 1111/j.1744-7909.2007.00442.x 
Li P, Dong $\mathrm{H}$, Zheng $\mathrm{C}$, et al. Optimizing nitrogen application rate and plant density for improving cotton yield and nitrogen use efficiency in the North China Plain. PLoS ONE. 2017;12(10): e0185550. https://doi.org/10. 1371/journal.pone.0185550.

Lin SH, Kuo HF, Canivenc G, et al. Mutation of the Arabidopsis NRT1.5 nitrate transporter causes defective root-to-shoot nitrate transport. Plant Cell. 2008;20(9):2514-28. https://doi.org/10.1105/tpc.108.060244.

Magwanga RO, Kirungu JN, Lu P, et al. Map-based functional analysis of the GhNLP genes reveals their roles in enhancing tolerance to N-deficiency in cotton. Int J Mol Sci. 2019;20(19):4953. https://doi.org/10.3390/ijms2 0194953.

Masclaux-Daubresse C, Daniel-Vedele F, Dechorgnat J, et al. Nitrogen uptake, assimilation and remobilization in plants: challenges for sustainable and productive agriculture. Ann Bot. 2010;105(7):1141-57. https://doi.org/10. 1093/aob/mcq028

McConnell JS, Mozaffari M. Yield, petiole nitrate, and node development responses of cotton to early season nitrogen fertilization. J Plant Nutr. 2005:27(7):1183-97. https://doi.org/10.1081/PLN-120038543.

Mng'omba SA, Akinnifesi FK, Kerr A, et al. Growth and yield responses of cotton (Gossypium hirsutum) to inorganic and organic fertilizers in southern Malawi. Agroforest Syst. 2017;91(2):249-58. https://doi.org/10.1007/ s10457-016-9924-0.

Niu J, Gui H, lqbal A, et al. N-use efficiency and yield of cotton (G. hirsutumn $\mathrm{L}$.) are improved through the combination of $\mathrm{N}$-fertilizer reduction and N-efficient cultivar. Agronomy. 2021;11(1):55. https://doi.org/10.3390/ agronomy 11010055.

OECD/FAO. OECD-FAO agricultural outlook 2020-2029. Paris: OECD Publishing; 2020. p. 212-6. https://doi.org/10.1787/1112c23b-en.

Raun WR, Johnson GV. Improving nitrogen use efficiency for cereal production. Agron J. 1999;91(3):357-63. https://doi.org/10.2134/agronj1999. $00021962009100030001 x$

Rogers GM, Poore MH, Paschal JC. Feeding cotton products to cattle. Vet Clin N Am Food A. 2002;18(2):267-94. https://doi.org/10.1016/S0749-0720(02) 00020-8.

Sandhu N, Sethi M, Kumar A, et al. Biochemical and genetic approaches improving nitrogen use efficiency in cereal crops: a review. Front Plant Sci. 2021;12(757): 657629. https://doi.org/10.3389/fpls.2021.657629.

Schauser L, Roussis A, Stiller J, et al. A plant regulator controlling development of symbiotic root nodules. Nature. 1999;402(6758):191-5. https://doi.org/ 10.1038/46058

Shah JM, Bukhari SAH, Zeng JB, et al. Nitrogen (N) metabolism related enzyme activities, cell ultrastructure and nutrient contents as affected by $\mathrm{N}$ level and barley genotype. J Integr Agric. 2017;16(1):190-8. https://doi.org/10. 1016/S2095-3119(15)61308-9.

Tiong J, Sharma N, Sampath R, et al. Improving nitrogen use efficiency through overexpression of alanine aminotransferase in rice, wheat, and barley. Front Plant Sci. 2021;12(29): 628521. https://doi.org/10.3389/fpls. 2021.628521.

Uauy C, Distelfeld A, Fahima T, et al. A NAC gene regulating senescence improves grain protein, zinc, and iron content in wheat. Science. 2006;314(5803):1298. https://doi.org/10.1126/science.1133649.

Wang X, Peng F, Li M, et al. Expression of a heterologous SnRK1 in tomato increases carbon assimilation, nitrogen uptake and modifies fruit development. J Plant Physiol. 2012;169(12):1173-82. https://doi.org/10.1016/j. jplph.2012.04.013.

Wu J, Zhang ZS, Xia JQ, et al. Rice NIN-LIKE PROTEIN 4 plays a pivotal role in nitrogen use efficiency. Plant Biotechnol J. 2020;19(3):448-61. https://doi. org/10.1111/pbi.13475

Xue XP, Sha YX, Guo WQ, et al. Accumulation characteristics of biomass and nitrogen and critical nitrogen concentration dilution model of cotton reproductive organ. Acta Ecol Sin. 2008;28(12):6204-11. https://doi.org/ 10.1016/S1872-2032(09)60015-9.

Yu LY, Wu J, Tang H, et al. Overexpression of Arabidopsis NLP7 improves plant growth under both nitrogen-limiting and -sufficient conditions by enhancing nitrogen and carbon assimilation. Sci Rep. 2016;6:27795. https://doi.org/10.1038/srep27795.

Zafar MM, Razzaq A, Farooq MA, et al. Insect resistance management in Bacillus thuringiensis cotton by MGPS (multiple genes pyramiding and silencing). J Cotton Res. 2020;3(1):33. https://doi.org/10.1186/s42397-020-00074-0.

Zhang $\mathrm{HH}$, Fu XQ, Wang XR, et al. Identification and screening of nitrogenefficient cotton genotypes under low and normal nitrogen environments at the seedling stage. J Cotton Res. 2018;1:6. https://doi.org/10.1186/ s42397-018-0006-X.
Ready to submit your research? Choose BMC and benefit from:

- fast, convenient online submission

- thorough peer review by experienced researchers in your field

- rapid publication on acceptance

- support for research data, including large and complex data types

- gold Open Access which fosters wider collaboration and increased citations

- maximum visibility for your research: over $100 \mathrm{M}$ website views per year

At BMC, research is always in progress.

Learn more biomedcentral.com/submissions 